\title{
Ganoderma lucidum: A Potent Medicinal Mushroom with Numerous Health Benefits
}

\section{Alok Nahata*}

Research and Development Manager, Ying Zhi Agricultural and Industries Sdn Bhd., Jitra-06000, Kedah, Malaysia

Herbal medicines which formed the basis of health care throughout the world since the earliest days of mankind are still attracting more and more attention within the context of health care provision and health sector reform. Recording of their clinical, pharmaceutical and economic value is encouraging for international trading, through it varies widely between countries.

A number of plant based traditional system of medicines have been in use in India and also in many parts of the world for ages. Before the advent of modern medicine, the traditional systems of medicine were playing a central role in healthcare. According to an estimate, majority of the world population, especially in the developing countries, still depend on herbal products for their primary health care needs, possibly for the following reasons:

1. Lack of easy access to drugs of modern medicine.

2. Popular belief that herbal drugs are free of adverse effects.

3. Most economic as against prohibitive cost of most of the allopathic drugs.

4. Concern over the toxicity and side effects of modern drugs.

5. The holistic approach and belief towards the plant based medicines.

The traditional medicine has been steadily gaining interest and acceptance even amongst the practitioners of modern medicine also [1]. Plants have also been a source of chemical substances which serves as drugs in their own right or as key ingredients in synthetic drugs. Many plants derived drugs used in modern medicine are developed by ethno medical leads and subsequent ethno pharmacological studies. There are more than 100 drugs of known structure that are extracted from higher plants and included in modern medicine [2]. A proper ethno pharmacological search and follow up studies can lead to many more useful drugs. Synthetic studies available on a good number of plants indicate that promising phytochemicals (drugs) can be developed for many health problems. This phytochemical approach of plant discovery emphasizes the development of pure phytochemicals as drugs. The method is expensive and much time consuming [3]. In phytotherapeutic approach, a fraction of an active extract or mixture of such fractions may prove better therapeutically, less toxic and inexpensive compared to pure isolated compounds. However crude plant preparations require modern standards of safety and efficacy.

\section{Ganoderma lucidum (Curtis) P. Karst}

\section{Family Ganodermataceae}

\section{Common Names}

United States : Reishi mushroom (Herbs of Commerce), ganoderma.

China : Ling zhi, ling zhi cao, ling chih, hong ling zhi, chi zhi

Japan : Reishi, mannentake; rokkakureishi (antler form).

Korea

$$
\text { : Young ji }
$$

\begin{tabular}{ll} 
Vietnam & : Ling chi \\
\multicolumn{2}{l}{ Taxonomical Classification } \\
Kingdom & : Fungi \\
Phylum & : Basidiomycota \\
Class & : Agaricomycetes \\
Order & : Polyporales \\
Family & : Ganodermataceae \\
Genus & $:$ Ganoderma \\
Species & $:$ G. lucidum
\end{tabular}

Numerous legends surrounding reishi mushroom provide an historical record which spans 2000 years. Traditionally, it was used in China by Taoist monks to promote a centered calmness, improve meditative practices, and attain a long and healthy life. Reishi mushroom has also been revered in Japanese culture where it is considered to be the most important of all the Japanese medicinal polypores [sarunokoshikake] [4]. The characters making up the Chinese name for reishi mushroom [ling zhi] originally depicted a "shaman crying for rain", represent the magical or divine properties which were associated with ling zhi. Reishi mushroom has also been commonly referred to as the "mushroom of immortality", "ten-thousand-year mushroom", "mushroom of spiritual potency", and "spirit plant" $[5,6]$. Reishi mushroom was listed among the superior tonics [Shang pin] in the most famous of all Chinese material medicas, the Shen Nung Ben Cao Jing (206 BC-AD 8) [4,7]. Superior herbs were among the most highly regarded of all medicines since they were considered to prolong life, prevent aging, boost qi, make the body light and limber, and corresponded to heavy heaven. Reishi mushroom was listed as the most respected out of the 120 superior tonics cited. Specifically, in this text, red reishi was reported to treat binding in the chest, tonify the heart, nourish the center, sharpen the wit, and improve memory. In addition to its physical properties, reishi was said to "cultivate virtue" [8,9].

\section{Work Done on the Phytochemical Profile}

Lalitha Kumari and Sirsi [10] partially purified the enzyme laccase from the culture fluid of Ganoderma lucidum by acetone precipitation,

*Corresponding author: Dr. Alok Nahata, M. Pharm., Ph.D., Research and Development Manager, Ying Zhi Agricultural and Industries Sdn Bhd., Jitra-06000, Kedah, Malaysia, E-mail: aloknahata@gmail.com,draloknahata@gmail.com

Received November 20, 2013; Accepted November 22, 2013; Published November 25, 2013

Citation: Nahata A (2013) Ganoderma lucidum: A Potent Medicinal Mushroom with Numerous Health Benefits Pharmaceut Anal Acta. 4: e159. doi: 10.4172/21532435.1000e159

Copyright: (c) 2013 Nahata A. This is an open-access article distributed under the terms of the Creative Commons Attribution License, which permits unrestricted use, distribution, and reproduction in any medium, provided the original author and source are credited. 
ammonium sulphate fractionation and adsorption on alumina $\mathrm{C} \gamma$ gel [10]. Kawagishi et al. [11] isolated a lectin (GLL-M) from mycelia of G. lucidum using affinity chromatography on BSM-Toy pearl [11]. Ko et al. [12] purified and characterized laccase isozymes from $G$. lucidum through anion exchange chromatography, preparative gel electrophoresis, and electroelution [12]. Bao et al. [13] studied the structural features of immunologically active polysaccharides from G. lucidum [13]. Guan et al. [14] carried out the structure elucidation and complete NMR spectral assignments of three new lanostanoid triterpenes with unprecedented $\delta 16,17$ double bond from G. lucidum [14]. Di et al. [15] carried out the fingerprint profiling of acid hydrolyzates of polysaccharides extracted from the fruiting bodies and spores of Lingzhi by high-performance thin-layer chromatography [15]. Gao et al. [16] carried out the quantitative determination of bitter principles in specimens of G. lucidum using High-Performance Liquid Chromatography and discussed its application to the evaluation of Ganoderma products [16]. Lim et al. [17] isolated a new inhibitor for peptidylprolylcis-trans isomerase (PPIase) from G. lucidum and purified to homogeneous state by organic solvent extraction. They also purified and characterized a new Cyclophilin Inhibitor from $G$. lucidum [17]. Mdachi et al. [18] identified sixteen known amino acids in G. lucidum [18]. Yan et al. [19] used the hybrid organic-inorganic monolithic column to separate triterpenoids from G. lucidum by capillary electro-chromatography [19]. Chen et al. [20] isolated Reishi polysaccharides for the study of their effect on cytokine expression in mouse splenocytes [20]. The conditions of polysaccharide production by G. lucidum were optimized by Babitskaya et al. [21]. Tang et al. [22] established that Ganoderic acid T from G. lucidum mycelia induces mitochondria mediated apoptosis in lung cancer cells [22]. Liu et al. [23] studied the structure-activity relationship for inhibition of 5a-reductase by triterpenoids isolated from G. lucidum [23]. Paterson (2006) [24] reviewed the phytochemical profile of Ganoderma and considered it to be a therapeutic fungal biofactory [24]. Wang and $\mathrm{Ng}$ (2006) [25] isolated Ganodermin, an antifungal protein from the fruiting bodies of G. lucidum [25]. Zhang et al. [26] developed a novel on-line system combining supercritical fluid extraction (SFE) and two dimensional high performance liquid chromatography (2D-HPLC) for the analysis of fruiting bodies of G. lucidum, and at least 73 components in the extract were resolved with calculated peak capacity of up to 1643 [26]. Wang et al. [27] developed a reversed-phase liquid chromatographic method for the quantitative determination of six triterpenoids, namely ganoderic acids $\mathrm{C} 2, \mathrm{~B}, \mathrm{AM} 1, \mathrm{~K}, \mathrm{H}$ and $\mathrm{D}$ in G. lucidum and its related species [27]. Tang et al. [28] carried out the separation of targeted ganoderic acids from $G$. lucidum by reversed phase liquid chromatography with ultraviolet and mass spectrometry detections [28]. Thakur et al. [29] purified and characterized a novel 114 $\mathrm{kDa}$ hexamericlectin from the fruiting bodies of G. lucidum [29]. Wang et al. [30] carried out the HPLC determination of four triterpenoids in rat urine after oral administration of total triterpenoids from $G$. lucidum [30]. Gao et al. [31] developed a high-performance liquid chromatography-diode array detector-mass spectrometry (HPLCDAD-MS) analytical method for detection of the nucleosides and nucleobases in G. lucidum [31]. Ye et al. [32] carried out the structural elucidation of the polysaccharide moiety of a glycopeptides (GLPCWII) from G. lucidum fruiting bodies [32].

\section{Work Done on the Pharmacological Profile}

Eo et al. [33] studied the antiherpetic activities of various protein bound polysaccharides isolated from G. lucidum [33]. Zhu et al. [34] studied the antioxidant activity of triterpenes from G. lucidum [34]. Gao et al. [35] studied the mechanism of the antiulcerogenic effect of G. lucidum polysaccharides on indomethacin-induced lesions in the rat [35]. Song et al. [36] assessed anti-angiogenic activity of $G$. lucidum and its inhibitory activity on inducible nitric oxide production in RAW 264.7 macrophages [36]. Lu et al. [37] established the fact that G. lucidum extracts inhibit growth and induce actin polymerization in bladder cancer cells in vitro [37]. Chien et al. [38] found that polysaccharides of G. lucidum alter cell immunophenotypic expression and enhance CD56+ NK-cell cytotoxicity in cord blood [38]. Liu et al. [39] have proposed a possible mode of action of antiherpetic activities of a proteoglycan isolated from the mycelia of G. lucidum in vitro [39]. Liu et al. [40] studied the anti-androgen effect of ganoderol B isolated from the fruiting body of G. lucidum [40]. Fujita et al. [41] established the anti-androgenic activities of methanol extracts of G. lucidum by performing the $5 \alpha$-reductase inhibitory activity [41]. Johnston [42] established the mechanism of action of G. lucidum against prostate cancer cells and found out that mushroom cuts off the blood supply to the prostate cancer cells [42]. Muller et al. [43] found out that G. lucidum causes apoptosis in leukemia, lymphoma and multiple myeloma cells. In this study, G. lucidum extract was screened for its anti-proliferative activity using a panel of 26 human cancer cell lines [43]. Lakshmi et al. [44] studied the antimutagenic activity of methanolic extract of $G$. lucidum and its effect on hepatic damage caused by benzo [a] pyrene [44]. Silva [45] published a guest editorial in Leukemia research emphasizing the importance of G. lucidum in cancer research [45]. Cao and Lin [46] established that G. lucidum polysaccharides peptide inhibits the growth of vascular endothelial cell and the induction of VEGF in human lung cancer cell [46]. Zhu and Lin [47] showed that G. lucidum polysaccharides (Gl-PS) have a variety of immune modulating effects. These polysaccharides can modulate of cytokine production, granzyme B and perforin in murine CIK cells [47]. Liu et al. [48] found out that the triterpenoids fraction of G. lucidum might be a useful ingredient in the treatment of benign prostatic hyperplasia [48]. Zhu et al. [49] found out that G. lucidum polysaccharides enhance the function of immunological effector cells in immunosuppressed mice [49]. Li et al. [50] indicated that G. lucidum polysaccharides have potent antioxidant properties in vitro in mitochondrial membranes of rat liver [50]. Ko et al. [51] explored the anti-inflammatory activity of triterpenoids and steroids from G. lucidum [51]. Ganoderma possesses the following pharmacological properties according to an overview of the American Herbal Pharmacopoeia (2006) [9].

Analgesic; anti-inflammatory; antitumor; antiviral hepatoprotective; hypoglycemic; hypocholesterolemic; hypotensive (ACE inhibitor); immune-modulating: increases IL-1- $\beta$, IL-2, and IL-6, increases cytotoxicity of T lymphocytes, increases TNF- $\alpha$ in macrophage cultures; inhibits platelet aggregation [9].

\section{Clinical Trials}

Ganoderma lucidum is reported to inhibit platelet aggregation [52, 53]; in immunologically compromised subjects, increases T lymphocyte and $\mathrm{T}$ helper cells and decreases $\mathrm{T}$ suppressor cells; improves immunocompetancy after chemo- and/or radiation therapies [54] Clinical information about the hepatoprotective action of reishi was reported in one small uncontrolled trial. Four patients with hepatitis $\mathrm{B}$ and elevated bilirubin and SGPT/SGOT levels were given $6 \mathrm{~g}$ of a reishi extract (concentration undefined) for 3 months. After 1 month, bilirubin, SGPT, and SGOT levels were significantly reduced $(P<0.01)$; after 90 days all values returned to within normal ranges [55]. Noguchi et al. [56] conducted a phase I clinical trial to evaluate the safety and efficacy of the extract of G. lucidum in men with mild symptoms of bladder outlet obstruction (BOO) [56]. 
Citation: Nahata A (2013) Ganoderma lucidum: A Potent Medicinal Mushroom with Numerous Health Benefits Pharmaceut Anal Acta. 4: e159. doi: 10.4172/2153-2435.1000e159

Page 3 of 4

\section{Work Undertaken by Our Group}

We carried out phytochemical and pharmacological investigations on G. lucidum for testing its anti-androgenic activity. We demonstrated the basis for the future use of Ganoderma in therapy by measuring the weekly urine output, testosterone levels and prostatic specific antigen levels using testosterone induced hyperplasia model in rats. Petroleum ether extract which remained untouched in the previous studies was included in the study and it came out to be the best inhibitor of prostatic hyperplasia induced by testosterone. Histological studies on the prostate sections also confirmed our findings [57]. It was also found to be a potent $5 \alpha$-reductase inhibitor on the basis of our studies which is indicative of the mechanism of its action against benign prostatic hyperplasia [57, 58]. $\beta$-sitosterol was identified in the Ganoderma extracts using TLC and HPTLC studies [57]. As $\beta$-sitosterol is a well-known molecule established clinically for the treatment of benign prostatic hyperplasia [59], the presence of $\beta$-sitosterol as a major constituent in the extracts further support our observations [57]. Certain studies on the in vitro cytotoxicity activity were also performed using G. lucidum extracts in human cancer cell lines [60].

\section{Pharmacological Activity and Uses}

It is considered to be a natural medicine that promotes longevity and maintains the vitality of human beings. Its beneficial clinical effects in patients with hepatitis, hyperglycemia, chronic bronchitis, cancer, muscular dystrophy, arteriosclerosis, hypertension, hypercholesterolemia, and leukopenia have been confirmed in pharmacologic studies in recent years. The fruiting bodies, mycelia, and spores have recently received more and more attention not only as home remedies but also as new drug sources [61].

\section{Conclusion}

Ganoderma lucidum has been widely researched and hence it has been a part of many publications as it is already evident from the literature cited above. Actually this literature constituted a part of literature survey carried by me during my studies on G. lucidum and I still find the compilation of these data worth sharable with the readers and various researchers. On the basis of many such evidences, there are many products in the market which are sold primarily as neutraceuticals. Some of them are marketed as dietary supplements and very widely used by consumers in combination with coffee and tea. Hence further research on Ganoderma for validating its usage is a demand of the present day.

\section{Acknowledgements}

I sincerely acknowledge the sources cited in this paper for elaborating in one way or the other about Ganoderma lucidum and its various aspects and carrying out some very interesting research on the mushroom.

\section{References}

1. Rajani M, Padh $H(2000)$ Fourth international symposium on innovations in pharmaceutical sciences and technology, Ahmedabad, India.

2. Cox PA (1994) The ethnobotanical approach to drug discovery: strength and limitations, In: Ethnobotany and the search for new drugs. Ciba Foundation Symposium, 184, Chichester, John Wiley and Sons: 25-41

3. Gupta SS (1994) Prospects and perspectives of natural products in medicine. Indian J Pharmacol 26: 1-12

4. Matsumoto K (1979) The Mysterious Reishi Mushroom. Santa Barbara: Woodbridge: 63

5. Huang KC (1993) The Pharmacology of Chinese Herbs. Boca Raton: CRC: 388
6. Liu B, Bau YS (1994) Fungi Pharmacopoeia (Sinica). Oakland: Kinoko: 297.

7. Unschuld P (1986) Medicine in China: A History of Pharmaceutics. Berkeley: Univ California Press: 366.

8. Yang SZ (1997) The Divine Farmer's MateriaMedica. Boulder (CO): Blue Poppy. Translation of: ShenNongBenCao Jing: 198.

9. American Herbal Pharmacopoeia (2006) Reishi Mushroom Ganoderma lucidum Standards of Analysis, Quality Control, and Therapeutics. In: Anonymous. American Herbal Pharmacopoeia and Therapeutic Compendium. American Herbal Pharmacopoeia: Scotts Valley, CA, USA: 10-12.

10. Lalithakumari H, Sirsi M (1972) Purification and Properties of Laccase from Ganoderma lucidum. Arch Mikrobiol84: 350-357.

11. Kawagishi H, Mitsunaga S, Yamawaki M, Ido M, Shimada A, et al. (1997) A lectin from mycelia of the fungus Ganoderma lucidum. Phytochem 44: 7-10.

12. Ko EM, Leem YE, Choi HT (2001) Purification and characterization of laccaseisozymes from the white-rot basidiomycete Ganoderma lucidum. ApplMicrobiolBiotechnol 57: 98-102.

13. Bao XF, Wang XS, Dong Q, Fang JN, Li XY (2002) Structural features of immunologically active polysaccharides from Ganoderma lucidum. Phytochemistry 59: 175-181.

14. Guan SH, Yang M, Wang XM, Xia JM, Zhang ZM, et al. (2007) Structure elucidation and complete NMR spectral assignments of three new lanostanoidtriterpenes with unprecedented $\delta 16,17$ double bond from Ganoderma lucidum. MagnResonChem 45: 789-791.

15. Di X, Chan KKC, Leung HW, Huie CW (2003) Fingerprint profiling of acid hydrolyzates of polysaccharides extracted from the fruiting bodies and spores of Lingzhi by high-performance thin-layer chromatography. J Chromatogr A 1018: 85-95.

16. Gao J, Nakamura N, Min B, Hirakawa A, Zuo F, et al. (2004) Quantitative Determination of Bitter Principles in Specimens of Ganoderma lucidum Using High-Performance Liquid Chromatography and Its Application to the Evaluation of GanodermaProducts. Chem Pharm Bull 52: 688-695.

17. Lim JI, Jeong KC, Kang I, Kim S (2004) A New Cyclophilin Inhibitor from Ganoderma lucidum: Purification and Characterization. Bull Korean ChemSoc 25: $1055-1060$.

18. Mdachi SJM, Nkunya MHH, Nyigo VA, Urasa IT (2004) Amino acid composition of some Tanzanian wild mushrooms. Food Chem 86: 179-182.

19. Yan L, Zhang Q, Zhang J, Zhang L, Li T, et al. (2004) Hybrid organic-inorganic monolithic stationary phase for acidic compounds separation by capillary electrochromatography. J Chromatogr A 1046: 255-261.

20. Chen HS, Tsai YF, Lin S, Lin CC, Khoo KH, Lin CH, Wong CH (2004) Studies on the immuno-modulating and anti-tumor activities of Ganoderma lucidum (Reishi) polysaccharides. Bioorg Med Chem 12: 5595-5601.

21. Babitskaya VG, Shcherba VV, Puchkova TA, Smirnov DA (2005) Polysaccharides of Ganoderma lucidum: Factors Affecting Their Production. Prikl Biokhim Mikrobiol 41: 169-173.

22. Tang W, Gu T, Zhong J (2006) Separation of targeted ganoderic acids from Ganoderma lucidum by reversed phase liquid chromatography with ultraviole and mass spectrometry detections. Biochemical Engineering Journal 32: 205210

23. Liu J, Kurashiki K, Shimizu K, Kondo R (2006) Structure-activity relationship fo inhibition of 5a-reductase by triterpenoids isolated from Ganoderma lucidum. Bioorg Med Chem 14: 8654-8660.

24. Paterson RRM (2006) Ganoderma - A therapeutic fungal biofactory. Phytochem 67: $1985-2001$

25. Wang $\mathrm{H}, \mathrm{Ng}$ TB (2006) Ganodermin, an antifungal protein from fruiting bodies of the medicinal mushroom Ganoderma lucidum. Peptides 27: 27-30.

26. Zhang J, Zhang L, Duan J, Liang Z, Zhang W, et al. (2006) On-line hyphenation of supercritical fluid extraction and two-dimensional high performance liquid chromatography-atmospheric pressure chemical ionization tandem mass spectrometer for the analysis of Ganoderma lucidum. J Sep Sci 29: 2514 -2522.

27. Wang XM, Yang M, Guan SH, Liu RX, Xia JM, et al. (2006) Quantitative determination of six major triterpenoids in Ganoderma lucidum and related species by high performance liquid chromatography. J Pharm Biomed Anal 41 838-844. 
Citation: Nahata A (2013) Ganoderma lucidum: A Potent Medicinal Mushroom with Numerous Health Benefits Pharmaceut Anal Acta. 4: e159. doi: $10.4172 / 2153-2435.1000 \mathrm{e} 159$

28. Tang W, Liu J, Zhao W, Wei D, Zhong J (2006) Ganoderic acid T from Ganoderma lucidum mycelia induces mitochondria mediated apoptosis in lung cancer cells. Life Sci, 80: 205-211.

29. Thakur A, Rana M, Lakhanpal TN, Ahmad A, Khan MI (2007) Purification and characterization of lectin from fruiting body of Ganoderma lucidum. Biochimicaet Biophysica Acta 1770: 1404-1412.

30. Wang XM, Guan SH, Liu RX, Sun JH, Liang Y, et al. (2007) HPLC determination of four triterpenoids in rat urine after oral administration of total triterpenoids from Ganoderma lucidum. J Pharm Biomed Anal 43: 1185-1190.

31. Gao JL, Leung KSY, Wang YT, Lai CM, Li SP, et al. (2007) Qualitative and quantitative analyses of nucleosides and nucleobases in Ganoderma spp. by HPLC-DAD-MS. J Pharm Biomed Anal 44: 807-811.

32. Ye LB, Zhang JS, Ye XJ, Tang QJ, Liu YF, et al. (2008) Structural elucidation of the polysaccharide moiety of a glycopeptide (GLPCW-II) from Ganoderma lucidum fruiting bodies. Carbo hydr Res 343: 746-752.

33. Eo SK, Kim YS, Lee CK, Han SS (1999) Antiherpetic activities of various protein bound polysaccharides isolated from Ganoderma lucidum. J Ethnopharmaco 68: $175-181$

34. Zhu M, Chang Q, Wong LK, Chong FS, Li RC (1999) Triterpene Antioxidants from Ganoderma lucidum. Phytother Res 13: 529-531.

35. Gao Y, Zhou S, Wen J, Huang M, Xu A (2002) Mechanism of the antiulcerogenic effect of Ganoderma lucidum polysaccharides on indomethacin-induced lesions in the rat. Life Sci 72: 731-745.

36. Song YS, Kim SH, Sa JH, Jin C, Lim CJ, et al. (2004) Anti-angiogenic and inhibitory activity on inducible nitric oxide production of the mushroom Ganoderma lucidum. J Ethnopharmacol 90: 17-20.

37. Lu QY, Jin YS, Zhang Q, Zhang Z, Heber D, et al. (2004) Ganoderma lucidum extracts inhibit growth and induce actin polymerization in bladder cancer cells in vitro. Cancer Lett 216: 9-20.

38. Chien CM, Cheng JL, Chang WT, Tien MH, Tsao CM, et al. (2004) Polysaccharides of Ganoderma lucidum alter cell immunophenotypic expression and enhance CD56+ NK-cell cytotoxicity in cord blood. Bioorg Med Chem 12: 5603-5609.

39. Liu J, Yang F, Ye LB, Yang XJ, Timani KA, et al. (2004) Possible mode of action of antiherpetic activities of a proteoglycan isolated from the mycelia of Ganoderma lucidum in vitro. J Ethnopharmacol 95: 265-272.

40. Liu J, Shimizu K, Konishi F, Kumamoto S, Kondo R (2007) The anti-androgen effect of ganoderol B isolated from the fruiting body of Ganoderma lucidum. Bioorg Med Chem 15: 4966-4972.

41. Fujita R, Liu J, Shimizu K, Konishi F, Noda K, et al. (2005) Anti-androgenic activities of Ganoderma lucidum. J Ethnopharmacol 102: 107-112.

42. Johnston N (2005) Medicinal mushroom cuts off prostate cancer cells' blood supply. Drug Discov Today 10: 1584

43. Müller Cl, Kumagai T, O’Kelly J, Seeram NP, Heber D, et al. (2006) Ganoderma lucidum causes apoptosis in leukemia, lymphoma and multiple myeloma cells. Leuk Res 30: 841-848.

44. Lakshmi B, Ajith TA, Jose N, Janardhanan KK (2006) Antimutagenic activity of methanolic extract of Ganoderma lucidum and its effect on hepatic damage caused by benzo[a]pyrene. J Ethnopharmacol 107: 297-303.

45. Sliva D (2006) Ganoderma lucidum in cancer research. Leuk Res 30: 767-768

46. Cao QZ, Lin ZB (2006) Ganoderma lucidum polysaccharides peptide inhibits the growth of vascular endothelial cell and the induction of VEGF in human lung cancer cell. Life Sci 78: 1457-1463.

47. Zhu X, Lin Z (2006) Modulation of cytokines production, granzyme B and perforin in murine CIK cells by Ganoderma lucidum polysaccharides. Carbohydr Polym 63:188-197.

48. Liu J, Shimizu K, Konishi F, Noda K, Kumamoto S, et al. (2007) Anti-androgenic activities of the triterpenoids fraction of Ganoderma lucidum. Food Chem 100 1691-1696.
49. Zhu XL, Chen AF, Lin ZB (2007) Ganoderma lucidum polysaccharides enhance the function of immunological effector cells in immunosuppressed mice. J Ethnopharmacol 111: 219-226.

50. Li XL, Zhou AG, Li XM (2007) Inhibition of Lyciumbarbarum polysaccharides and Ganoderma lucidum polysaccharides against oxidative injury induced by Y-irradiation in rat liver mitochondria. Carbohydrate Polymers 69: 172-178.

51. Ko HH, Hung CF, Wang JP, Lin CN (2008) Antiinflammatory triterpenoids and steroids from Ganoderma lucidum and G. tsugae. Phytochemistry 69: 234-239.

52. Cheng Z, Wang J, Shao Y, Liang Z, Ning Y, et al. (1993) Effects of ling zh on hemorrheology parameters and symptoms of hypertension patients with hyperlipidemia and sequelae of cerebral thrombosis. In: Zhu S, Mori M, editors. The Research on Ganoderma lucidum (Part One). Volume 1. Shanghai: Shanghai Med Univ: 339-342.

53. Tao J, Feng KY (1990) Experimental and clinical studies on inhibitory effect of Ganoderma lucidum on platelet aggregation. J Tongji Med Univ 10: 240-243.

54. Kupin V (1992) A new biological response modifier Ganoderma lucidum and its application in oncology. In: Proceedings of the 4th international symposium on Ganoderma lucidum. Cancer Res Ctr: 49-50.

55. Soo TS (1994) The therapeutic value of Ganoderma lucidum. In: Buchanan PK Hseu RS, Moncalvo JM, (eds). Ganoderma systematics, phytopathology and pharmacology. Proceedings of contributed symposium 59A, B; 5th International Mycological Congress; 1994 Aug 14-21; Vancouver. Place of publication unavailable: Publisher unavailable: 105-113

56. Noguchi M, Kakuma T, Tomiyasu K, Konishi F, Kumamoto S, et al. (2005) Phase I study of a methanol extract of Ganoderma lucidum, edible and medicinal mushroom, in men with mild symptoms of bladder outlet obstruction. Urology 66: 21.

57. Nahata A, Dixit VK (2012) Ganoderma lucidum is an inhibitor of testosteroneinduced prostatic hyperplasia in rats. Andrologia 44: 160-174.

58. Nahata A, Dixit VK (2013) Evaluation of $5 \alpha$-reductase inhibitory activity of certain herbs useful as antiandrogens. Andrologia doi: 10.1111/and.12115.

59. Wilt TJ, MacDonald R, Ishani A (1999) beta-sitosterol for the treatment of benign prostatic hyperplasia: a systematic review. BJU Int 83: 976-983.

60. Nahata A, Saxena A, Suri N, Saxena AK, Dixit VK (2013) Sphaeranthus indicus induce apoptosis through mitochondrial-dependent pathway in HL-60 cells and exerts cytotoxic potential on several human cancer cell lines. Integr Cancer Ther 12: 236-247.

61. Gao JJ, Nakamura N, Min BS, Hirakawa A, Zuo F, et al. (2004) Quantitative determination of bitter principles in specimens of Ganoderma lucidum using high-performance liquid chromatography and its application to the evaluation of ganoderma products. Chem Pharm Bull (Tokyo) 52: 688-695 